\title{
Diffusion Tensor Imaging studies: white matter fibre alterations in Anorexia Nervosa (a systematic review)
}

\author{
Beatriz Martin ${ }^{1 *}$, Phillipa Hay ${ }^{1}$, Stephen Touyz ${ }^{2}$, Nasim Foroughi ${ }^{1}$ \\ From 2015 ANZAED Conference: Riding the Waves to Recovery \\ Surfers Paradise, Australia. 21-22 August 2015
}

\section{Introduction}

Diffusion Tensor Imaging technique (DTI) is a rapidly evolving procedure available for characterising abnormalities in white matter fibre structure (WM) in relation to neuropathology and treatment.

\section{Objective}

to investigate the association of WM fibre tracts and microstructural alterations in Anorexia Nervosa (AN).

\section{Method}

A systematic database search for published studies was conducted in November 2014 on 4 databases to identify studies that included samples of individuals with AN in which WM fibre tracts were analysed by means of DTI.

\section{Results}

A total of 20 studies were retrieved, from which 6 met the inclusion criteria. The study samples were comprised of recovered patients $(n=4)$, patients in the ill acute state $(\mathrm{n}=1)$, and both $(\mathrm{n}=1)$. Preliminary evidence suggests the WM fibre of the fornix, the cingulum, and the frontooccipital fibre tracts are altered in AN patients but the persistence with or without recovery is less clear.

\section{Conclusion}

The selected studies expose diverse altered tracts in AN, mainly related to the limbic system and some prefrontal areas. The varying findings may reflect its symptom complexity. The DTI technique appears to be well suited to examine the neurological underpinnings of AN. Further

* Correspondence: B.MartinMonzon@westernsydney.edu.au

${ }^{1}$ Western Sydney University, Sydney, Australia

Full list of author information is available at the end of the article research is needed to study putative alterations in patients who recover and in those who do not recover.

\section{Authors' details}

'Western Sydney University, Sydney, Australia. ${ }^{2}$ University of Sydney, Sydney, Australia.

Published: 23 November 2015

doi:10.1186/2050-2974-3-S1-P11

Cite this article as: Martin et al:: Diffusion Tensor Imaging studies: white matter fibre alterations in Anorexia Nervosa (a systematic review). Journal of Eating Disorders 2015 3(Suppl 1):P11.
Submit your next manuscript to BioMed Central and take full advantage of:

- Convenient online submission

- Thorough peer review

- No space constraints or color figure charges

- Immediate publication on acceptance

- Inclusion in PubMed, CAS, Scopus and Google Scholar

- Research which is freely available for redistribution
() Biomed Central 